\title{
Images and voices from digital Africa
}

\author{
Part II: Mobile apps for the illiterate. Knowledge production \\ and self-learning among the Yoruba peoples in the Republic of Benin
}

Aimé Dafon Sègla, Université d'Abomey-Calavi, Republic of Benin (a_s_aime@yahoo.fr)

Mobile phones and web digital tools contribute to the personal development of the individual and his or her capacity to develop initiatives e.g. for economic growth. Yet, many people cannot benefit from new technologies as digital services in sub-Saharan Africa are mostly configured in foreign languages. Illiteracy and language barriers remain a major challenge for digitalization in Africa. However, the case of Yoruba illiterates in the central Republic of Benin shows that indigenous people are innovative and create new procedural knowledge. They have developed alternative strategies to benefit from information and communications technology (ICT). Based on approximately 50 interviews with traders, peasants, art craft (wo)men, and members of convents, my ethnographic research explores how the Yoruba people of Benin utilize mobile phones in their mother tongue.

\section{Obstacles to using mobile phones}

Mobile phones and web services in sub-Saharan Africa are primarily configured in foreign languages. In post-colonial Benin French is still the official language, even though most people can only communicate in one of the country's fourty dialects. Digital services rely mostly on written words and are not designed in local dialects. Hence, illiteracy and language barriers remain a major challenge for digitalization in Africa.

Yoruba illiterates struggle with the use of information and communications technology: they are not able to buy airtime (credit) for their phones and often do not know their own mobile phone numbers. Illiterate people are disadvantaged when it comes to using services that are provided through mobile phones since they cannot make backups of names and phone numbers of their contacts.

This is an article distributed under the terms of the Creative Commons Attribution License CCBY 4.0 (https://creativecommons.org/licenses/by/4.0/)

https://doi.org/10.14512/tatup.28.2.s50

\section{Exclusive communications}

Illiterates cannot consult and read the information about their credit accounts, so they ignore their balances. They even miss important information: Since her old model Nokia that talked to her before has fallen out of use since Biaou Victorine, aged 52, an illiterate peasant living in Diho in the District of Shabè, has been unable participate in community exchanges, or receive information on governmental information campaigns. What is more, these campaigns on vital issues like reproduction, vaccination against malaria, polio or diseases like cholera are posted in French language on mobile operators' platforms.

\section{Illiteracy and creative appropriation of mobile phones}

Owolabi Josephine, a 35 years old trader from Alafia in the District of Shabè land, says: "To know that my credits or data expired, I look if a non-turning circle appears on WhatsApp. I then know I have no more data or credits. But when it turns, it means the network is available, so my credits are not finished".

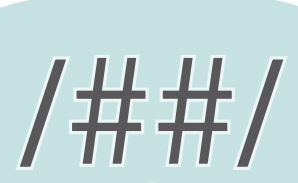

a
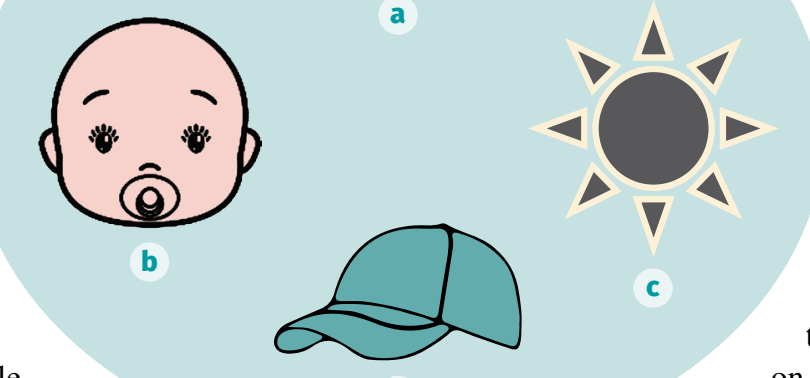

d
Some illiterate Yoruba use digital services such as WhatsApp for voice messaging, but this requires expensive data plans. Instead, many illiterate Yoruba use the alphanumerical signs and symbols available in a phone's keyboard repertoire, like @, \#, ?, !, *, +, \, ^, and so on. They give these signs particular meanings for their specific purposes. For example, during the backup process for data saved on the phone, they learn to name the file to be saved with a particular sign. Monsia Félicienne, a 85 years old illiterated tradeswoman in Diho (Savè), states: "Every sign [on my mobile phone's directory] carries a specific meaning and is attributed to a person. I asked to put a car to identify the phone number of my boy, because I pray he is rich one day and can buy 
a car; I have a grandson whose contact is identified by a ball, because he plays football and I wish he became like Pokou Laurent, former football star in Ivory Coast. To identify the contact of my Babalawo Priest, I put a cat's head because for me his work relates to the cat, the symbol of witchcraft ... that's how I identify my contacts".

When illiterate Yoruba exhaust the stock of the signs on the conventional mobile phone, they continue to innovate this symbol based language by introducing numbers; then, they make use of object symbols, like flowers, plants, and other images of the fauna or of their immediate environment. The most skilled people learn to imagine and use compositions of different symbols, or of alphanumeric characters.

a) The combination of hashtags and slashes identifies the contact of a carpenter.

b) The image of a baby identifies the contact of a daughter in the telephone directory. It is motivated by wishing the daughter fertility.

c) The image of the sun identifies the contact of a daughter who lives in Niamey, the capital of Niger, which is situated in a desert.

d) The hat identifies the contact of a village chief.

\section{Mobile app solutions for illiterate people}

While the illiterate Yoruba of Benin cannot access any written information, they can identify symbols and record as well as listen to audio messages on their mobile phones. Ethnography clearly reveals what Africanizing ICT means. Mobile apps must operate in local languages, for example in Yoruba. The mobile app “JE M'EDUQUE”, currently under development, will provide an adaptation of the current state of technology by adding new mother tongue language support, extended use of symbols, for example from traditoinal cultural knowledge, translation applications, or audio signals to confirm the arrival of money transfers.

\section{Incorporating traditional cultural knowledge into technology}

When the signs, symbols, and objects on conventional phones are exhausted, those Yoruba who know about ancient rites and traditions opt for Àrokò traditional symbols for message trans- mission. In traditional Yoruba culture Àrokò is used to shorten the message transfer:

e) A chief would send his hat to fighting parties as a request for peace.

f) Two cowrie shells facing each other indicate agreement with a course of action/decision.

g) One king would send his flywhisk to the other in a request for solidarity and support.

Thus, by integrating Àrokò traditional codes into the further development of conventional mobile phones, illiterate Yoruba can extend their means of expression.

\section{Localizing social media}

Providing social media in subSaharan languages will demonstrate the fundamental role of

ICT in promoting and accelerating the education of the most marginalized. It can help educate the illiterate about climate change, sustainable development, or gender equality, and provide new services and employment opportunities in the rural areas, such as online medicine, accounting and rural affairs management. Adapting ICT to local specificity is a precondition for equitable opportunities and for removing the barriers and inequalities exacerbated today by globalization.

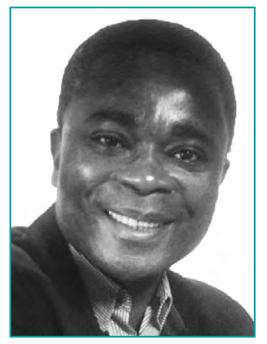

\section{DR. AIMÉ DAFON SĖGLA}

has been trained as an engineer and holds a PhD in history and philosophy of science and technology. As a researcher A. D Sègla has been working on the anthropology of knowledge in non-Western cultures with affiliations at, for example, Université d'Abomey-Calavi in the Republic of Benin, or the Max-Planck-Institute, Germany. He also works as independent consultant in Paris. 